\title{
IMPLEMENTASI CONSIGNMENT STOCK DAN MARKETING MIX STRATEGY 4P UNTUK MENURUNKAN PERSEDIAAN PADA PART AND SERVICE DEPARTMENT DI PT. COAL MINING
}

\section{THE IMPLEMENTATION OF CONSIGNMENT STOCK AND MARKETING MIX STRATEGY 4P TO REDUCE INVENTORIES IN PART AND SERVICE DEPARTMENT IN PT. COAL MINING}

\section{Hery Hamdi Azwir ${ }^{1^{*}}$, Arif Hidayatulloh², Hirawati Oemar ${ }^{2}$}

1,2) Program Studi Teknik Industri, Universitas Presiden, Jababeka, Cikarang, Bekasi 17530, Indonesia

3) Program Studi Teknik Industri, Universitas Islam Bandung, Bandung 40116, Indonesia

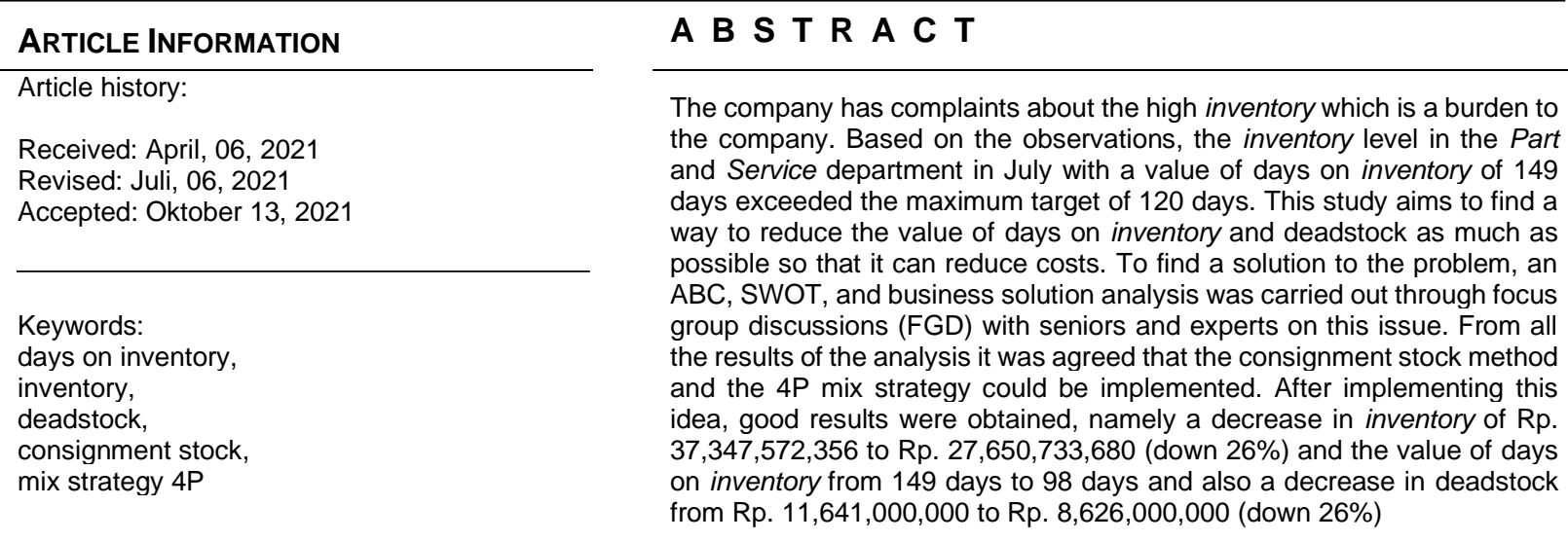

\section{A B S T R A K}

Kata Kunci :

days on inventory,

persediaan

deadstock,

consignment stock

mix strategy $4 P$

\begin{abstract}
Perusahaan memiliki keluhan akan tingginya inventory (inventory) yang menjadi beban bagi perusahaan. Berdasarkan hasil observasi, tingkat inventory pada DePartemen Part and Service pada bulan Juli 2018 ditemukan nilai days on inventory sebesar 149 hari yang mana telah melebihi batas maksimum yaitu 120 hari. Penelitian ini bertujuan untuk menemukan cara agar nilai days on inventory dan deadstock dapat ditekan semaksimal mungkin sehingga dapat menekan cost. Untuk mencari solusi permasalahan dilakukan analisis ABC, SWOT, dan solusi bisnis melalui focus group discussion (FGD) dengan para senior dan ahli dalam masalah ini. Dari seluruh hasil analisis disepakati bahwa metode consignment stock dan mix strategy 4P lah yang dapat diimplementasikan. Setelah implementasi ide tersebut, didapatkan hasil yang baik yakni penurunan inventory Rp 37.347.572.356 menjadi Rp 27.650.733.680 (turun 26\%) serta nilai days on inventory dari 149 hari menjadi 98 hari dan juga penurunan atas deadstock dari $\mathrm{Rp} 11.641 .000 .000$ menjadi $\mathrm{Rp}$ 8.626.000.000 (turun 26\%).
\end{abstract}

This is an open access article under the $\underline{\mathrm{CC}-\mathrm{BY}}$ license.

*Corresponding Autho

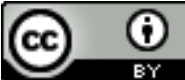

Hery Hamdi Azwir

E-mail: hery.azwir@president.ac.id 


\section{PENDAHULUAN}

PT COAL MINING adalah salah satu perusahaan multinasional yang bergerak di bidang manufaktur alat-alat berat pertambangan. Perusahaan ini selalu mengedepankan pelayanan serta inovasi untuk terus bisa memanjakan serta memudahkan customer-nya. Untuk tujuan tersebut, perusahaan juga menyediakan suku cadang (spare part) untuk menjamin layanan setelah penjualan. Layanan penyediaan suku cadang ini juga berkontribusi cukup besar pada keuntungan perusahaan. Karena itu, bisnis tersebut di dalam struktur organisasi perusahaan dikelola oleh unit khusus yaitu Part and Service Department.

Namun, banyaknya komponen suku cadang dan ketidakpastian permintaan membuat penanganan terhadap inventory menjadi tidak mudah untuk dilakukan. Pada saat penelitian ini dilakukan, telah terjadi Ionjakan signifikan nilai inventory pada bulan Juli 2018 dibanding bulan-bulan sebelumnya, sehingga menimbulkan pertanyaan. Total inventory pada periode bulan Februari sampai bulan Juli 2018 cenderung meningkat dan puncaknya di bulan Juli mencapai Rp 37.347.572.356, dengan total penjualan / Cost Of Gods Sold (cogs) sebesar Rp 46.017.427.964. Pada bulan tersebut diketahui pula telah terjadi banyak deadstock dengan jumlah $\mathrm{Rp}$ 11.641.000.000. Kemudian dari nilai tersebut jumlah inventory turn-over semakin kecil dan nilai days on inventory atau tingkat pengendapan material semakin tinggi. Hal ini memberi indikasi terjadinya ketidakstabilan terhadap pengelolaan inventory yang menyebabkan tingginya nilai days on inventory pada bulan tersebut.

Keadaan tersebut jika dibiarkan maka lambat laun akan menggerogoti profit yang didapatkan oleh perusahaan, sehingga diperlukan solusi untuk mengatasinya. Ada banyak sekali metode yang tersedia untuk mengatasi problem manajemen inventory ini, baik melalui pendekatan secara saintifik maupun melalui pendekatan yang lebih bersifat praktis dan lebih mudah untuk diterapkan. Pendekatan secara saintifik umumnya memerlukan dukungan ketersedian data yang cukup lengkap dan dapat diandalkan (reliable).

Untuk pendekatan secara saintifik, Axater [1] menjelaskan dengan sangat baik banyak aspek dalam pengendalian inventory (inventory control). Axater menjelaskan bahwa pengendalian selalu dimulai dengan melakukan peramalan (forecasting) yang tepat. Setelah itu dilanjutkan dengan mengenali struktur biayanya dan barulah menentukan metode pengendalian yang sesuai. Dalam penentuan metode pengendalian hal yang harus dipahami juga adalah mengenai posisi inventory, level inventory, dan skema pemantauan inventorynya apakah secara kontinu (real-time) atau periodik saja. Terakhir yang tidak tertinggal adalah mengenai kebijakan pemesanan (ordering policies) yang dipilih, kapan melakukan pemesanan dan berapa banyak kuantitas pemesanan. Selanjutnya Axater membagi pengendalian inventory berdasarkan kategori single-echelon, multiple-echelon, dan terdapat pula kasus yang berupa joint replenishment.

Beberapa studi terkait pengendalian persediaan diantaranya: pengelolaan gudang suku cadang mengandalkan sistem informasi [2], penggunaan metode fixed time period [3], metode EOQ untuk mengelola inventory kantung darah di PMI [4], pengembangan model inventory dengan mempertimbangkan inventory, harga jual dan faktor deteriorasi [5], menggunakan vendor managed inventory (VMI) [6], penerapan kebijakan back-order dan lost sales [7], aplikasi metode $A B C$ analysis [8], pentingnya aplikasi EDI agar informasi untuk kebutuhan pengendalian inventory dapat tersedia dan andal [9], aplikasi konsep min-max untuk pengendalian inventory spare part [10], penggunaan model inventory single-item untuk pengelolaan spare-parts forklift [11].

Berdasarkan situasi yang dihadapi perusahaan, maka tujuan dari studi ini adalah melakukan perbaikan terhadap proses perencanaan serta pengendalian inventory agar dapat menurunkan tingkat days on inventory sehingga sumber daya yang mengendap bisa ditekan semaksimal mungkin. Pendekatan yang akan dilakukan lebih bersifat best-practice yang lebih mudah untuk diterapkan dalam lingkungan organisasi perusahaan namun cukup efektif dalam mencapai tujuan yang diharapkan.

Pendekatan pengendalian inventory umumnya banyak berbasiskan pemodelan yang tentu menuntut suatu asumsi tertentu juga didukung dengan kelengkapan data yang akurat. Namun dalam implementasinya adanya asumsi-asumsi seringkali menyulitkan dan terlalu menyederhanakan masalah, padahal situasi sebenarnya lebih kompleks. Wild [12] mengatakan bahwa banyak pendekatan yang lebih praktis dalam mengelola inventory yang telah terbukti meningkatkan profitabilitas perusahaan karena kunci kesuksesan bisnis adalah layanan konsumen. Studi ini mengusulkan kombinasi pendekatan Marketing mix 4P dan konsinyasi stok (consignment stock). Marketing mix 4P merupakan strategi pemasaran yang memadukan product, place, price, dan promotion agar customer tertarik dengan produk yang ditawarkan [13]. Sedangkan konsinyasi stok 
adalah bentuk kerjasama antara penjual dan pembeli yang dituangkan dalam suatu kesepakatan terkait pembelian atau penjualan dan penyimpanan barang [14]. Valentini dan Zavanella [15] mengatakan bahwa dengan mengabungkan kepraktisan dari kebijakan min$\max (\mathrm{s}, \mathrm{S})$ dan pendekatan sistem dari model memaksimalkan keuntungan bersama, konsinyasi stok dapat mengungguli model inventory biasa. Konsinyasi stok tidak hanya dapat menghemat biaya inventory tapi juga memberikan fleksibilitas, dapat meningkat mutu layanan dalam situasi yang dinamis, dan meningkat hubungan kerjasama antara penjual dan pembeli [15] [16] [17].

Namun konsinyasi stok lebih fokus pada bagaimana mengatur kesepakatan antara penjual dan pembeli sehingga keduanya dalam posisi yang sama-sama diuntungkan. Jika dikaitkan dengan kepentingan penjualan, tentu penjual mengharapkan produknya sebanyak mungkin dapat terjual termasuk semua produk yang berada dalam status deadstock. Karena itu perlu ada pendekatan lain yang dapat membantu mempercepat berkurangnya stok yang tentu menjadi beban. Karena itulah dalam makalah ini diusulkan Marketing Mix 4P sebagai solusi untuk mempercepat penjualan sekaligus menurunkan stok yang masih tertahan termasuk deadstock.

\section{METODOLOGI PENELITIAN}

Penelitian ini dimulai dengan observasi terhadap profil perusahaan, sektor bisnis perusahaan hingga sampai pada bagian / lokasi penelitian dilakukan yang terkait beberapa poin penting sehingga dapat tergambarkan secara utuh.

Pengambilan data dilakukan untuk semua data berhubungan dengan tingginya jumlah inventory, yaitu meliputi :

1. Data Finance \& Accounting Department (Nilai Penjualan / Cogs, Nilai Inventory, Jumlah Days On Inventory

2. Data Production Plan \& Inventory Control Department (Monthly Stock Inventory, Deadstock, Current Method Planning Inventory \& Inventory Control)

3. Data Marketing And Sales Department (Sales Order Product PT. COAL MINING 2018)

Setelah itu dilakukan pengolahan data dan dilanjutkan dengan analisis untuk menemukan akar masalah dengan menggunakan beberapa metode analisis yaitu :

\section{Root Cause Analysis \\ 3. SWOT Analysis \\ 4. Analisis Solusi Bisnis \\ 5. Consignment stock \\ 6. Marketing Mix 4P}

\section{1. $A B C$ Analysis}

Dalam Analisis $A B C$, inventory dibagi menjadi tiga kelas berdasarkan nilai penjualan dalam setahun [12].

- Kelas A - Nilai penjualan tahunan tinggi

- Kelas B - Nilai penjualan tahunan sedang

- Kelas C - Nilai penjualan tahunan rendah.

Analisis difokuskan pada penetapan kebijakan untuk jenis-jenis inventory yang penting berdasarkan nilai penjualannya. Sehingga hasil pengelompokannya adalah sebagai berikut:

Klasifikasi A : apabila penjualan / konsumsi material terjadi sebanyak 11 sampai 12 bulan dalam setahun ( $20 \%$ material)

Klasifikasi B : apabila penjualan / konsumsi material terjadi sebanyak 7 sampai 10 bulan dalam setahun ( $30 \%$ material)

Klasifikasi C : apabila penjualan / konsumsi material terjadi sebanyak 1 sampai 6 bulan dalam setahun $(50 \%$ material)

\subsection{Root Cause Analysis}

Ada banyak metodologi Root Cause analysis [18]. Namun secara umum metodologi ini dapat membantu kita untuk menelusuri akar masalah sehingga dengan ditemukannya penyebab, maka perbaikan yang akan dilakukan menjadi efektif. Salah satu metode yang populer adalah analisis menggunakan fishbone diagram. Dengan fishbone diagram, akar masalah dapat ditelusuri hingga ke hulunya.

\subsection{SWOT Analysis}

SWOT Analysis [19]. Merupakan suatu strategi perencanaan untuk melakukan evaluasi terhadap kekuatan (strength), kelemahan (weakness), peluang (opportunity), serta ancaman (threats). Analisis SWOT diwujudkan dalam bentuk tabeltabel yang mengidentifikasi faktor inti yang datang dari lingkungan internal dan eksternal. Faktor internal yakni faktor yang berasal dari dalam suatu organisasi atau perusahaan yaitu faktor kekuatan dan kelemahan, sedangkan faktor eksternal yakni merupakan faktor yang datang dari luar organisasi atau perusahaan yaitu faktor peluang dan ancaman.

\section{1. $A B C$ Analysis}




\subsection{Analisis Solusi Bisnis}

Analisis solusi bisnis yang dimaksud adalah upaya untuk mencari alternatif solusi yang layak secara bisnis untuk diimplementasikan. Alternatif solusi merupakan hasil dari kegiatan FGD (focus group discussion). Pencarian solusi dilakukan berdasarkan atas temuan yang diperoleh saat dilakukan $A B C$ analysis, Fishbone diagram dan juga SWOT analysis

\subsection{Consignment Stock}

Setelah keempat proses analisis dilakukan maka selanjutnya adalah melakukan proses perbaikan (improvement). Proses perbaikan ini dilakukan dengan menggunakan konsep konsinyasi stok (consignment stock) dikombinasikan dengan strategi Marketing mix 4P. Sederhananya, konsinyasi adalah penjualan dengan cara pemilik menitipkan barang kepada pihak lain untuk dijualkan dengan harga dan syarat yang telah diatur dalam suatu kesepakatan [15].

\subsection{Marketing Mix 4P}

Salah satu strategi pemasaran yang dapat digunakan untuk menunjang keberhasilan penjualan produk adalah Marketing mix 4P melalui analisis product, price, place, dan promotion. Setelah dilakukan analisis Marketing Mix 4P maka dilanjutkan dengan menyusun strategi perbaikan dan implementasinya. Terakhir, dilakukan analisis perbandingan kondisi sebelum dan setelahnya.

\section{HASIL DAN PEMBAHASAN}

\subsection{Observasi Awal}

Perusahaan memberikan target terhadap Part and Service Department (PSD) yaitu days on inventory 120 hari, sebagai parameter pengukuran terhadap kinerja inventory dan nilai ini menjadi Key
Performance Indicator (KPI) bagi PSD di tahun 2018 sebagaimana dijelaskan dalam Gambar 1.

Dalam KPI yang diperlihatkan pada Gambar 1, dapat ditunjukkan bahwa perusahaan memiliki dua goal yaitu WIG (widely important goal) dan IG (important goal). Setelah KPI ini diterjemahkan ke level departemen, dalam hal ini PSD, ditemukan target important goal pada bagian yang diberi warna kuning dan dilingkari yaitu "maintain spare Parts Dol 120 days in 2018". Ini adalah target yang ditetapkan oleh manajemen dan menjadi KPI Departemen.

Namun, diketahui berdasarkan laporan oleh Financial and Accounting Department dibulan juli 2018, days on inventory dari PSD ternyata berada dikisaran149 hari inventory mengendap di dalam perusahaan sebagaimana diperlihatkan dalam Tabel 1 , yang nyatanya melebihi target didalam KPI dari PSD yakni 120 hari.

\subsection{Pengumpulan Data}

\subsubsection{Data Finance And Accounting}

Berdasarkan pengumpulan data yang diperoleh dari departemen Finance and Accounting didapatkan informasi yaitu adanya peningkatan nilai cogs dari Februari sampai Juli 2018, yang diperlihatkan Gambar 2. Didapati juga nilai inventory yang cenderung meningkat dari bulan Februari sampai dengan Juli 2018, yang ditunjukkan pada Gambar 3. Begitu pula days on inventory juga mengalami tren meningkat, sebagaimana ditunjukkan dalam Gambar 4, Padahal targetnya adalah maksimum 120 hari.

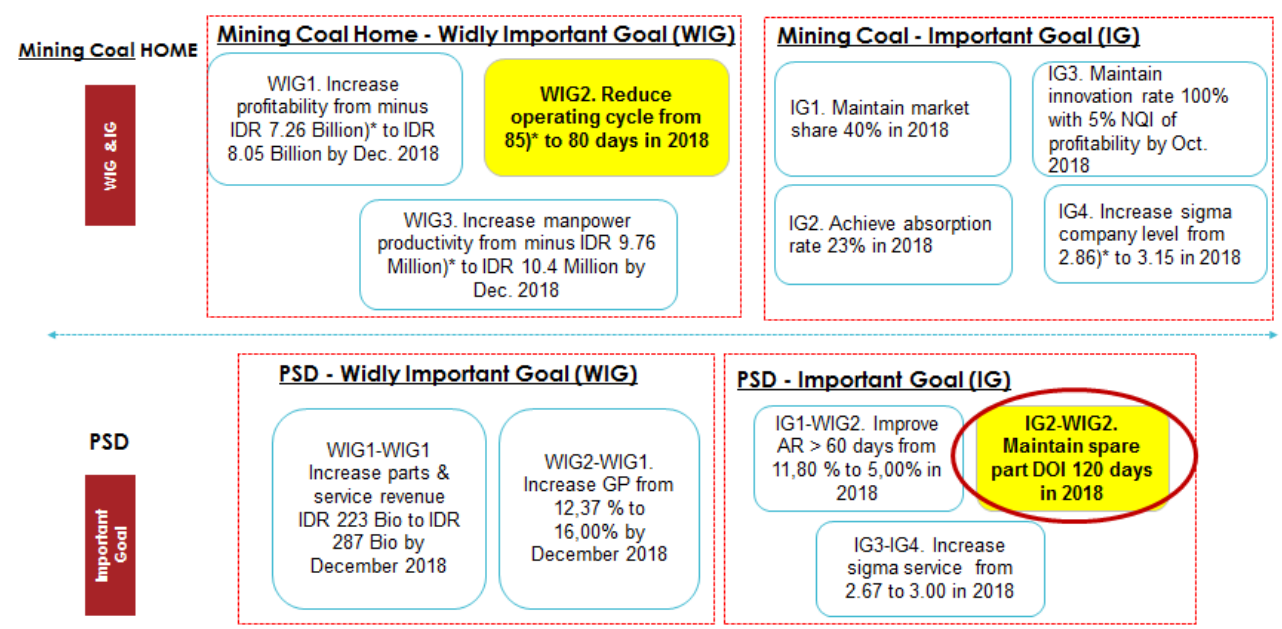

Gambar 1. Key Performance Indicator 
Tabel 1. Rangkuman inventory Juli 2018

\begin{tabular}{|c|c|c|}
\hline \multicolumn{3}{|c|}{ PT MINING COAL } \\
\hline \multicolumn{3}{|c|}{ Summary Inventory } \\
\hline \multicolumn{3}{|c|}{ PERIODE Juli 2018} \\
\hline Account & Inventories & Jul '18 \\
\hline & Inventory - Raw Material & \\
\hline 1150131200 & Inventory - Finished Units - Parts & . \\
\hline 1150140000 & Inventory - Spareparts & 38.350 .519 .805 \\
\hline \multirow[t]{3}{*}{1150150010} & Inventory - Consumables Production & \\
\hline & $\begin{array}{l}\text { Total Raw, Spareparts, and } \\
\text { Cons }\end{array}$ & 38.350 .519 .805 \\
\hline & Total Inventories & 38.350 .519 .805 \\
\hline \multirow[t]{5}{*}{1150261100} & Allowance for Obsolenscence & $(1.002 .947 .449)$ \\
\hline & Total & 37.347.572.356 \\
\hline & COST OF GOODS SOLD & 46.017.427.964 \\
\hline & TOTAL COGS & 46.017.427.964 \\
\hline & DAYS ON INVENTORY & 149 \\
\hline
\end{tabular}

\section{COGS PER FEB-JULI 2018}

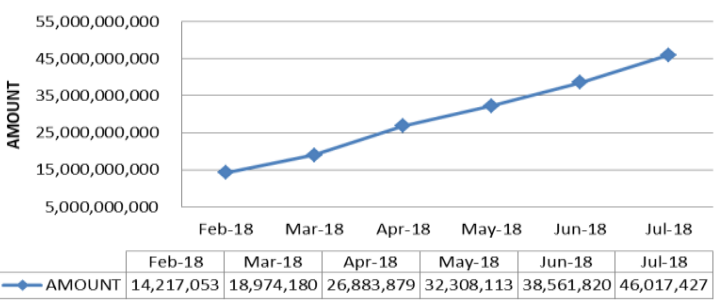

Gambar 2. Cogs Part and Service Department Periode Februari-Juli 2018

\section{INVENTORY PER FEB-JULI2018}

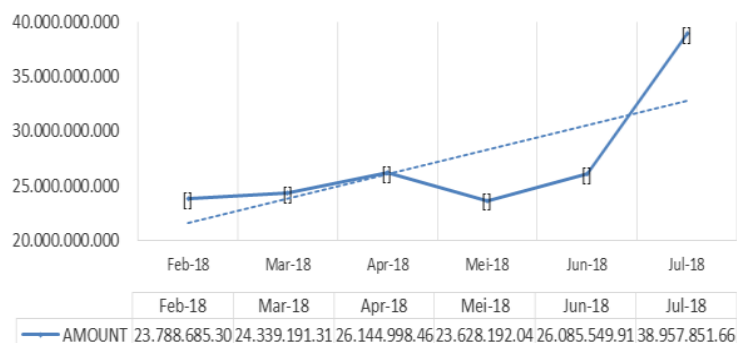

Gambar 3. Inventory Part and Service Department Februari-Juli 2018

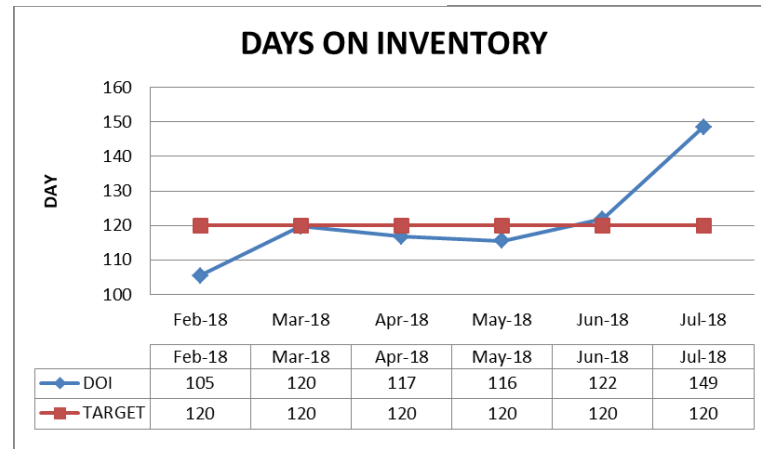

Gambar 4. Days on inventory Part and Service Department Februari-Juli 2018

\subsubsection{Data Production Plan And Inventory Control (PPIC)}

Data selanjutnya diperoleh dari departemen PPIC, dimana diketahui bahwa pada bulan Juli 2018 terjadi kenaikan yang cukup tinggi pada inventory PSD dari data tersebut ditemukan bahwa nilai deadstock berdasarkan sistem pengelolaan inventory yang diterapkan saat itu adalah 11 Milyar lebih sebagaimana yang diperlihatkan dalam Tabel 2. Ini adalah suatu jumlah yang sangat besar.

Tabel 2. Deadstock inventory

\begin{tabular}{rlccr}
\hline No & Vendor & $\begin{array}{c}\text { Jumlah Part } \\
\text { Number }\end{array}$ & $\begin{array}{c}\text { Jumlah } \\
\text { Part (PCS) }\end{array}$ & $\begin{array}{r}\text { Amount } \\
\times 1.000 \text { (IDR) }\end{array}$ \\
\hline 1 & BPW & 50 & 19633 & 4.004 .000 \\
2 & KUBOTA & 354 & 8934 & 2.124 .000 \\
3 & PATRIA & 361 & 29186 & 1.725 .000 \\
4 & YORK & 12 & 1830 & 598.000 \\
5 & INDEXATOR & 5 & 80 & 460.000 \\
6 & VICKERS & 7 & 24 & 285.000 \\
7 & INTERLUBE & 16 & 401 & 262.000 \\
8 HELI & 66 & 268 & 228.000
\end{tabular}




\begin{tabular}{rlccr}
\hline No & Vendor & $\begin{array}{c}\text { Jumlah Part } \\
\text { Number }\end{array}$ & $\begin{array}{c}\text { Jumlah } \\
\text { Part (PCS) }\end{array}$ & $\begin{array}{r}\text { Amount } \\
\times 1.000 \text { (IDR) }\end{array}$ \\
\hline 9 & CIMC & 6 & 133 & 218.000 \\
10 & KHITCH & 2 & 46 & 165.000 \\
11 & OTHERS & 155 & 6906 & 1.654 .000 \\
\multicolumn{1}{c}{ Total } & 1034 & 67441 & 11.641 .000 \\
\hline
\end{tabular}

Perusahaan sebenarnya telah memiliki ERP yaitu SAP yang powerful dan sudah memiliki modul untuk membantu mengelola inventory. Namun kenyataannya sumber daya ini belum sepenuhnya termanfaatkan akibat belum adanya aturan atau kebijakan yang disepakati bersama terkait manajemen inventory untuk dapat diimplementasikan. Hal ini diperlihatkan pada Gambar 5. dimana fitur reorder point dan maximum stock level tidak digunakan.

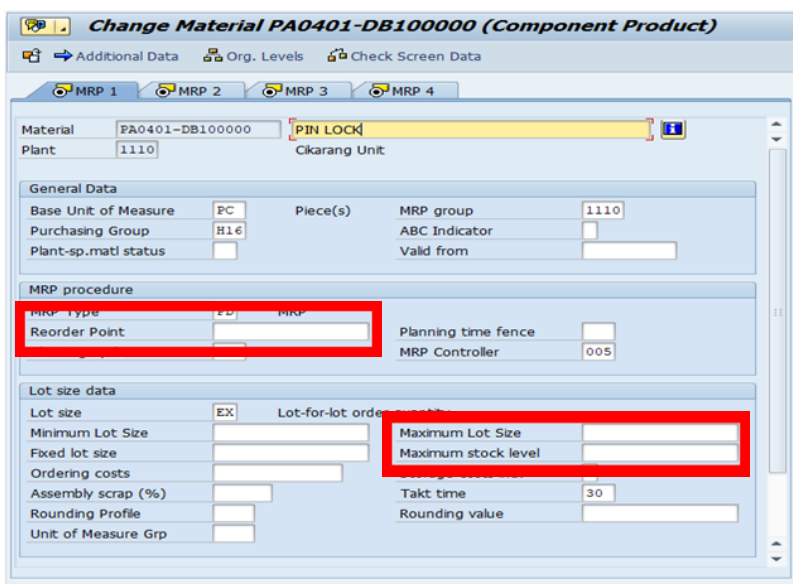

Gambar 5. Kondisi awal pengendalian inventory di SAP.

Dalam membuat perencanaan stok Parts. Departemen Production hanya mengandalkan pada perkiraan bahwa permintaan di tahun berikutnya akan naik sebesar $10-20 \%$. Tentu saja, metode ini tidak memiliki dasar yang kuat dan bisa dipertanggung jawabkan. Akibatnya, hasil akhirnya adalah banyak stok yang menumpuk karena jumlah permintaan tidak sebesar yang diperkirakan.

\subsubsection{Marketing And Sales Department}

Data yang diperoleh dari Departemen Marketing and Sales yaitu terkait Sales Order unit atau produk-produk PT. COAL MINING ditahun 2018 dapat ditunjukkan pada Tabel 3. Terlihat bahwa customer terbesarnya adalah PT United Tractors, Tbk.

Tabel 3. Sales Order

\begin{tabular}{llrr}
\hline No & Deskripsi customer & $\begin{array}{l}\text { Qty } \\
\text { Produk }\end{array}$ & \multicolumn{2}{l}{$\begin{array}{l}\text { Sales } \\
\text { Amount } \\
\text { X } 1000(\mathrm{Rp})\end{array}$} \\
\hline 1 & KALIMANTAN PRIMA & 7 & 5.044 .800 \\
2 & PERSADA & 94 & 71.224 .000 \\
3 & SAMAPERSADA NUSANTARA & 99 & 117.150 .000 \\
4 & UNITED TRACTORS TBK & 526 & 300.603 .178
\end{tabular}

\begin{tabular}{lll}
\hline No Deskripsi customer & $\begin{array}{l}\text { Qty } \\
\text { Produk }\end{array}$ & $\begin{array}{l}\text { Sales } \\
\text { Amount } \\
\text { X 1000 (Rp) }\end{array}$ \\
\hline Total & 726 & 494.021 .978 \\
\hline
\end{tabular}

\subsection{Analisis Data}

Setelah mendapatkan informasi dari tiga sumber data yaitu departemen: Finance dan Accounting; PPIC; Marketing dan Sales, maka selanjutnya dilakukan analisis menggunakan $\mathrm{ABC}$, Root Cause, SWOT, dan solusi bisnis.

\subsubsection{ABC Analysis}

Dari hasil analisis ditemukan yang termasuk dalam kategori Klasifikasi A : yaitu apabila pergerakan material/ konsumsi material terjadi pada 11 sampai 12 bulan dalam setahun ternyata tidak ada sehingga klasifikasi hanyalah $B$ dan C saja.

Berdasarkan perhitungan dengan menggunakan analisis $A B C$ maka didapatkan hasil sebagai mana yang diperlihatkan dalam $\underline{\text { Tabel } 4}$.

Tabel 4. Klasifikasi pergerakan bulanan inventory Part and Service Department

\begin{tabular}{ccccc}
\hline No & $\begin{array}{c}\text { Jumlah } \\
\text { Part } \\
\text { number }\end{array}$ & $\begin{array}{c}\text { Jumlah } \\
\text { (pcs) }\end{array}$ & Amount (IDR) & Klasisifikasi \\
\hline 1 & 3 & 300 & 1.112 .603 .506 & B \\
2 & 297 & 42853 & 6.462 .997 .696 & C \\
3 & 1733 & 98375 & 29.771 .971 .154 & Unclasssify \\
Total & 2033 & 141528 & 37.347 .572 .356 & - \\
\hline
\end{tabular}

Kemudian juga ditemukan klasifikasi yang dapat dikategorikan unclassify yaitu tidak ada permintaan atau pergerakan terhadap material selama satu tahun terakhir, namun terdapat jumlah stok yaitu 1733 jenis material atau Part dengan jumlah 98375 pcs dengan nilai total 29.771.971.154. Hasil tersebut menunjukkan bahwasa terjadi ketidakstabilan terhadap pengelolaan inventory, sehingga dibutuhkan metode yang lebih tepat terhadap pengelolaan inventory yang ada saat ini

\subsubsection{Root Cause Analysis}

Tahap selanjutnya yakni dilakukan analisis menggunakan fishbone diagram yang dapat dapat dilihat pada Gambar 6. Dari hasil analisis menggunakan diagram tulang ikan tersebut didapati akar masalah yang ternyata lebih cenderung ke pada metode yang masih belum tepat. Penjelasannya adalah sebagai berikut: 
Tabel 5. Rangkuman hasil analisis

\begin{tabular}{|c|c|c|}
\hline Tools Analysis & Hasil & Kesimpulan \\
\hline & $\begin{array}{l}\text { klasifikasi B : } 3 \text { Part Number } \\
\text { dengan jumlah } 300 \text { pcs Material }\end{array}$ & \\
\hline ABC Analysis & $\begin{array}{l}\text { Klasikasi C : } 297 \text { Part Number } \\
\text { dengan jumlah } 42853 \text { Material } \\
\text { Not Requirement : } 1733 \text { Part } \\
\text { Number dengan jumlah } 98375 \\
\text { Material }\end{array}$ & $\begin{array}{l}\text { Hasil menunjukkan terjadi } \\
\text { ketidakstabilan terhadap pengelolaan } \\
\text { inventory, sehingga dibutuhkan metode } \\
\text { pengelolaan inventory }\end{array}$ \\
\hline \multirow{2}{*}{$\begin{array}{l}\text { Root Cause } \\
\text { Analysis }\end{array}$} & $\begin{array}{l}\text { Tidak Ada Metode Pengelolaan } \\
\text { inventory }\end{array}$ & $\begin{array}{l}\text { Dibutuhkan Metode Pengelolaan } \\
\text { inventory }\end{array}$ \\
\hline & $\begin{array}{l}\text { Tidak Ada Metode Pengelolaan } \\
\text { Deadstock }\end{array}$ & $\begin{array}{l}\text { Dibutuhkan Metode pengelolaan } \\
\text { Deadstock }\end{array}$ \\
\hline \multirow[t]{2}{*}{ SWOT Analysis } & $\begin{array}{l}\text { Melakukan ekspansi penjualan } \\
\text { produk ke sektor lain } \\
\text { Melakukan pembaruan sistim } \\
\text { kerja sama suku cadang } \\
\text { melalui kontrak konsinyasi } \\
\text { penyediaan suku cadang } \\
\text { Melakukan mix strategy } 4 P\end{array}$ & \multirow[t]{2}{*}{$\begin{array}{l}\text { Adanya kesempatan kerjasama dengan } \\
\text { customer sebagai peluang strategi } \\
\text { bisnis. }\end{array}$} \\
\hline & $\begin{array}{l}\text { Melakukan optimalisasi } \\
\text { peramalan inventory suku } \\
\text { cadang melalui ERP (SAP) }\end{array}$ & \\
\hline
\end{tabular}

Tabel 6. Asumsi EOQ \& consignment stock

\begin{tabular}{|c|c|c|}
\hline No & EOQ & Consignment \\
\hline 1 & $\begin{array}{l}\text { Tingkat permintaan (jumlah unit per periode } \\
\text { waktu) diketahui \& konstan artinya tersebar } \\
\text { merata disepanjang waktu. }\end{array}$ & $\begin{array}{l}\text { Permintaan diketahui dalam satu } \\
\text { tahun dan diikat dengan } \\
\text { perjanjian }\end{array}$ \\
\hline 2 & $\begin{array}{l}\text { Pengiriman ke pelanggan dilakukan segera, } \\
\text { jadi tidak boleh terjadi kekurangan (shortage) }\end{array}$ & $\begin{array}{l}\text { Pengiriman dilakukan segera } \\
\text { setelah didapatkan permintaan } \\
\text { dari pelanggan }\end{array}$ \\
\hline 3 & $\begin{array}{l}\text { Waktu tunggu pengiriman konstan (itu tidak } \\
\text { tergantung pada ukuran pesanan atau } \\
\text { kapasitas proses pengiriman pemasok) }\end{array}$ & $\begin{array}{l}\text { Waktu tunggu pengiriman } \\
\text { konstan }\end{array}$ \\
\hline 4 & $\begin{array}{l}\text { Biaya per unit konstan dan diketahui (itu } \\
\text { tidak tergantung pada ukuran pesanan; tidak } \\
\text { ada diskon jumlah dan tidak berubah } \\
\text { disepanjang waktu) }\end{array}$ & $\begin{array}{l}\text { Biaya per unit konstan dan } \\
\text { diketahui }\end{array}$ \\
\hline 5 & $\begin{array}{l}\text { Biaya tetap per pesanan konstan dan } \\
\text { diketahui (itu tidak tergantung pada ukuran } \\
\text { pesanan; tidak ada diskon jumlah dan tidak } \\
\text { berubah disepanjang waktu). }\end{array}$ & $\begin{array}{l}\text { Biaya tetap per pesanan } \\
\text { konstan dan diketahui }\end{array}$ \\
\hline 6 & $\begin{array}{l}\text { Biaya penyimpanan inventory per unit per } \\
\text { periode adalah konstan dan diketahui }\end{array}$ & $\begin{array}{l}\text { Tidak ada biaya penyimpanan } \\
\text { inventory }\end{array}$ \\
\hline 7 & $\begin{array}{l}\text { Tujuannya adalah untuk meminimalkan total } \\
\text { biaya per periode }\end{array}$ & $\begin{array}{l}\text { Tujuannya adalah untuk } \\
\text { meminimalkan total biaya per } \\
\text { periode dan memperluas } \\
\text { pemasaran serta } \\
\text { memperbanyak jumlah } \\
\text { penjualan }\end{array}$ \\
\hline
\end{tabular}


Tabel 7. Rangkuman hasil FGD

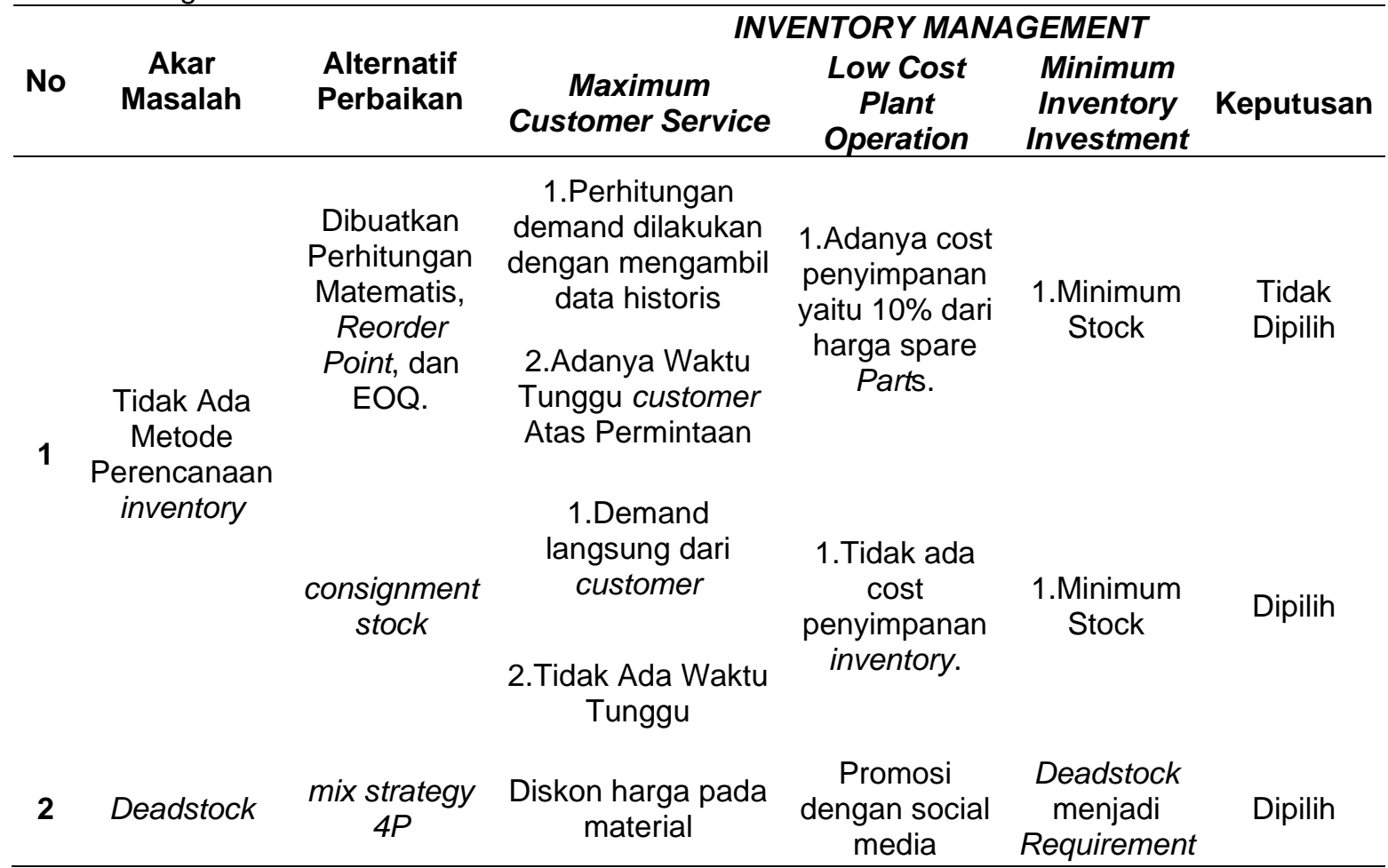

Ada banyak model inventory control yang telah dipublikasikan baik model inventrory control yang bersifat umum maupun yang khusus dalam manajemen spare parts [20] namun yang menjadi masalah adalah keterbatasan skill dan knowledge dari para staff yang menanganinya. Aplikasi suatu metode yang bersifat lanjut dan spesifik tentu menuntut skill dan knowledge yang baik dari penggunannya. Dengan alasan tersebut diusulkan model inventory control yang paling umum dan relatif tidak terlalu sulit untuk dipahami yaitu EOQ karena untuk kasus ini dapat digolongkan dalam single-echelon dengan asumsi deterministik sebagai alternatif pertama. Untuk alternatif yang kedua adalah melakukan kerjasama penjualan consignment stock sebagai metode yang dirasa cukup apllicable dan tidak terlalu sulit untuk diimplementasikan.

Selanjutnya kedua alternatif tersebut dievaluasi, untuk menentukan metode yang lebih sesuai, efektif diterapkan dan cocok dengan situasi dan kondisi yang ada saat itu di perusahaan. Perbandingan kedua metode tersebut dapat dilihat pada Tabel 6 .

Dalam menentukan metode yang paling tepat maka yang menjadi pertimbangan utama adalah bahwa metode terpilih harus berkontribusi pada: (1) Investasi inventory minimum; (2) Maksimasi Customer Service; dan (3) Biaya operasional plant rendah. Untuk itu diadakanlah focus group discussion (FGD) selama empat minggu dengan melibatkan seluruh pemangku kepentingan (stake holder) yaitu Manager Marketing and Sales, Manager PPIC, Staff PPIC, Manager Accounting and Procurement, dan Manager Part and Service. Hasil dari FGD dapat dirangkum dalam Tabel 7.

\subsection{Perbaikan}

Pada tahap ini dilakukan implementasi terhadap ide perbaikan yang telah dibahas dalam FGD yakni ada dua ide perbaikan yang dapat menurunkan jumlah inventory yang tinggi, yaitu: (1) Penjualan Konsinyasi (consignment stock); (2) mix strategy $4 P$.

\subsubsection{Penjualan Konsinyasi}

Pada perbaikan ini tahap-tahap yang dilakukan yaitu dimulai dengan meeting consignment seperti terlihat pada Gambar 8, kemudian dilakukan sebuah kesepakatan seperti terlihat pada Gambar $\underline{9}$. Selanjutnya setelah didapatkan kesepakatan kemudian customer memberikan forecast demand yang dikirimkan melalui e-mail, contohnya Gambar 10, yang kemudian output nya adalah input pengelolaan inventory pada SAP, sebagaimana ditunjukkan pada Gambar 11.

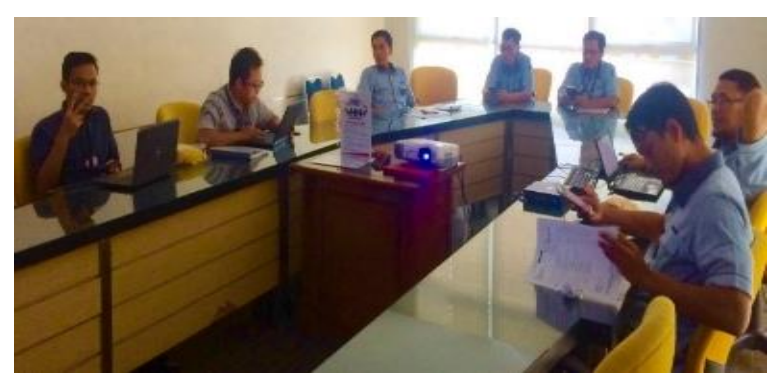


Gambar 8. Meeting consignment

\begin{tabular}{l} 
Perjanjian Consignment \\
\hline Kesepakatan ini berlangsung selama satu tahun. \\
\hline $\begin{array}{l}\text { Harga part tetap selama periode kesepakatan (tidak terjadi prubahan } \\
\text { harga part). }\end{array}$ \\
\hline $\begin{array}{l}\text { Pihak customer (penerima titipan) memberikan forecast permintaan } \\
\text { selama satu tahun. }\end{array}$ \\
\hline Dilakukan review permintaan selama 3 bulan sekali \\
\hline $\begin{array}{l}\text { Material / part yang sudah dikirim masih menjadi inventory pengirim } \\
\text { sampai dilakukan pengambilan atau pemakaian terhadap part tersebut } \\
\text { oleh customer. }\end{array}$ \\
\hline Jumlah Material / part yang tertulis didalam forecast harus dibeli. \\
\hline
\end{tabular}

Gambar 9. Perjanjian consignment.

Gambar 11 memperlihatkan bahwa data reorder point dan maximum stock level di-input berdasarkan forecast yang telah ditetapkan oleh customer sendiri. Jadi ini akan meminimalkan usaha yang dilakukan oleh perusahaan untuk melakukan melakukan forecasting.

\subsubsection{Mix Strategy 4P}

Perbaikan kedua yaitu dengan implementasi metode mix strategy $4 P$ (product, place, price, promotion). Strategi Marketing Mix 4P yang diimplementasikan dapat dideskripsikan sebagaimana diperlihatkan pada Gambar 12.

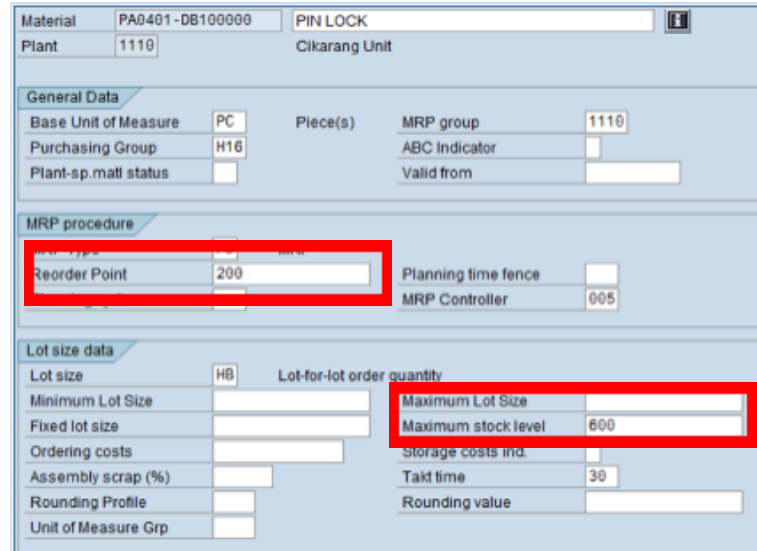

Gambar 11. SAP setelah dilakukan perbaikan.

Langkah 1. Product

Pada sistem pemasaran produk yang dimaksud dapat diartikan bagaimana mengembangkan barang atau jasa terhadap sasaran pasar yang tepat. Artinya produk harus sesuai dengan kebutuhan pasar yang menjadi target. Disini dibahas sifat-sifat dari berbagai produk tersebut diantaranya yaitu: (1) Keadaan / kualitas barang; (2) Konsumen yang dituju, contohnya adalah perusahaan sebagaimana yang ditunjukkan Gambar 13; (3) Suasana pasar. Langkah yang dilakukan adalah mengumpulkan data deadstock, mencek kondisi fisik dan mengklasifikasikan berdasarkan brand.

PT PAMAPERSADA NUSANTARA
Jt.Rawagelam I No.9 Kawasan Industri Pulogadung , Jakarta 13930
Telp : $(021) 4602015$
Supply Management Coal Hauler Department
Site Adaro - Pasar Panas
Ji. Haul Road Km 25 Adaro Coal Mining Project Kal-Sel

\begin{tabular}{|c|c|c|c|c|c|c|}
\hline \multicolumn{2}{|c|}{ DISTRACT } & \multicolumn{5}{|l|}{ : ADHO } \\
\hline \multicolumn{2}{|c|}{ WAREHOUSE } & \multicolumn{5}{|l|}{ : TEPS } \\
\hline \multicolumn{2}{|c|}{ NOMOR } & \multicolumn{5}{|c|}{ : ADRO/SMCH/BAST-VHS/2018/019 } \\
\hline \multicolumn{2}{|c|}{ TANGGAL } & \multicolumn{5}{|c|}{ : 11-02-2019 } \\
\hline No & Stock cose & Mneneric & part No & UTE Dart Na & men Name & Mn \\
\hline 2 & 259510 & Baw & 03.109 .77 .43 .0 & VRBP0 $1-10005-380$ & ERAKE OSUM FOR SINGE MUT & 8 \\
\hline 3 & $18 \$ 63$ & BXW & 310577619 & VRBP201 $60001-352 A$ & BRAKE DQUM FOR DOLELE NUT & 32 \\
\hline 4 & $208 s 128$ & EW & 311276130 & VRE $=02-60061-1340$ & Qusiang stetve & 59 \\
\hline 5 & 53405 & B2W & 318502020 & VRAP01-20002-325 & RaNG IOOKING METAL, ORJM COVER & $10:$ \\
\hline 6 & 1505890 & Baw & 326217200 & VFBP01-00001-446 & CASTLE MUT & 12 \\
\hline
\end{tabular}

Gambar 10. Email forecast customer 


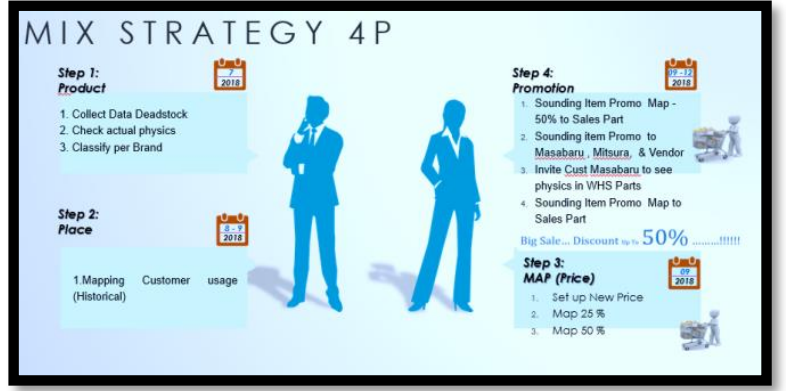

Gambar 12. Mix strategy $4 P$
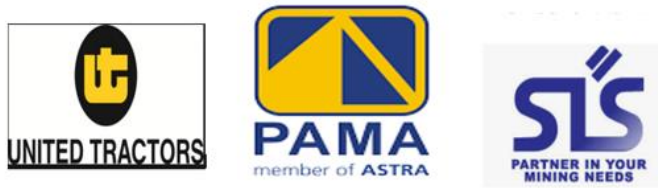

Gambar 13. customer PT Coal Mining

Langkah 2. Place

Pembahasan tentang tempat yakni mengenai bagaimana kegunaan produk terhadap sasaran pasar, karena suatu produk tidak lagi menjadi barang yang dibutuhkan oleh para pembeli ketika barang tersebut tidak tersedia disaat yang tepat pada waktu yang dibutuhkan oleh pembeli.

Pada tahap ini dilakukan pemetaan terhadap sasaran pasar karena produk yang dijual saat ini yaitu spare part dengan status deadstock maka ada beberapa tipe customer yang dituju yaitu: (1) customer loyal yaitu customer yang sudah lama bekerjasama sehingga lebih mudah menawarkan; (2) customer baru yaitu mau membeli karena percaya pada nama besar perusahaan; (3) customer price-minded yaitu customer yang lebih sensitif pada harga tapi kurang terhadap mutu produk sehingga cocok ditawarkan produk deadstock; (4) customer yang tidak terikat KPI, yaitu ada beberapa tipe customer yang memiliki keleluasaan dalam membeli tanpa adanya keterikatan prosedur yang mengharuskan untuk membeli spare part dalam keadaan baru.

\section{Langkah 3. Price}

Penentuan harga dapat berdasarkan depresiasi harga atas usia barang mengendap didalam gudang perusahaan. Dalam kasus ini, bagaimana cara mengubah barang deadstock, contohnya ada pada Gambar 14, menjadi barang yang dapat dijual dan memenuhi permintaan customer atau pasar. Ketika spare part sudah dalam status deadstock sebenarnya secara value sudah nol karena depresiasi nya sudah $100 \%$. Jadi dihargai berapapun sebenarnya sudah bisa untung, namun untuk dapat menjualnya diperlukan proses "vermak" misalkan repainting agar produk tersebut tampilannya kembali menarik sehingga memiliki value. Strategi berikutnya adalah ditetapkanlah dua periode harga atas spare part untuk keperluan promosi. Periode pertama antara bulan Juli sampai dengan Agustus dan periode ke dua September sampai dengan Desember. Untuk periode pertama disepakati moving average price (diskon) $30 \%$ sedangkan untuk periode kedua moving average price (diskon) 50\%.

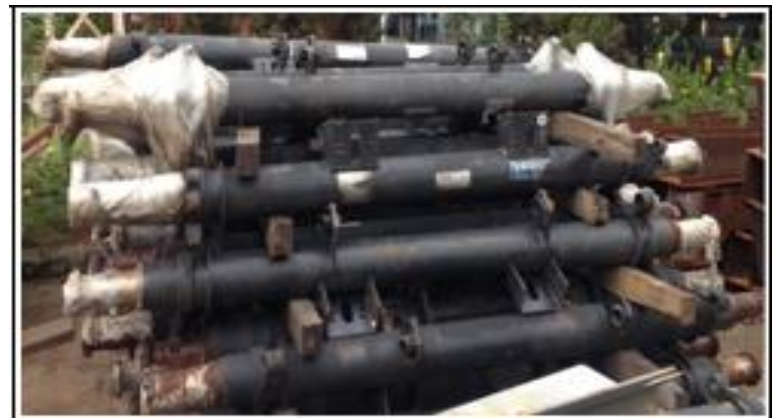

Gambar 14. Deadstock Part

\section{Langkah 4. Promotion}

Promosi yaitu suatu aktifitas pemberitaan terhadap sasaran pasar atau masyarakat luas tentang suatu produk. Promosi dapat dilakukan dengan cara publikasi, contohnya Gambar 15, perorangan (personal selling) via email, misal Gambar 16, atau dengan cara sales promotion, sebagaimana Gambar 17.

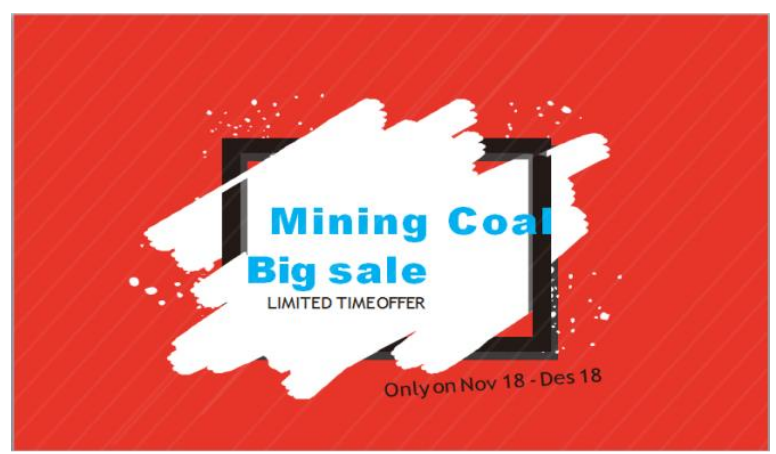

Gambar 15. Publikasi

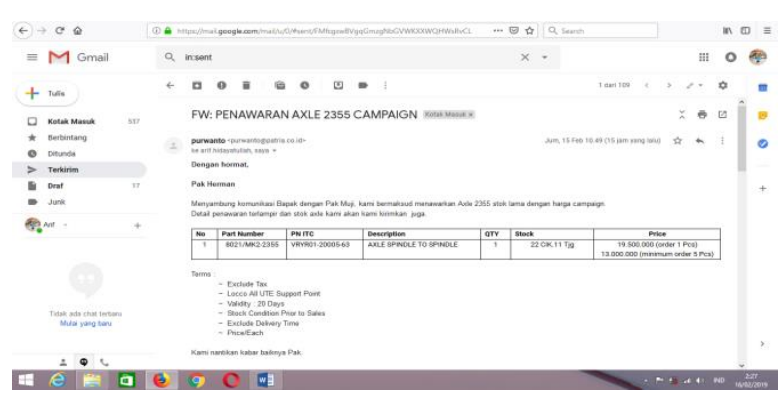

Gambar 16. Personal selling via email 


\section{Kubota Parts}

\begin{tabular}{|c|c|c|c|c|c|c|c|}
\hline NO & Vendor & PN PATRIA & PNORI & Material Description & QTY & Normal Price/PC & Promo Price/PC \\
\hline 1 & KUBO & $1 \approx 24123014$ & 1234123014 & CRNKSWFT & 17 & $18.012 .300,00$ & 5.944 .050 \\
\hline 2 & KUBO & 1907703040 & $19077-03048$ & COMP.CLREAD & 1. & $16.751 .500,00$ & 4.930 .165 \\
\hline 3 & $\begin{array}{r}\text { KUBO } \\
\text { TA }\end{array}$ & 1664123010 & 1664123010 & COMPCRANK SHAT & 11 & 15.468.700,00 & 5.104 .654 \\
\hline 4 & $\begin{array}{r}\text { KUBO } \\
\text { TA }\end{array}$ & $15 \times 276012$ & $15527-6012$ & MOTOR, ENGNESTAFIIREECIRCAL & 1 & 14.883.900,00 & 4.8 \\
\hline 5 & $\begin{array}{r}\text { KUBO } \\
\text { TA }\end{array}$ & 1605203040 & 1605203044 & CYNDERHEADASSY & 11 & $14.076 .800,00$ & 4.024 .727 \\
\hline 6 & $\begin{array}{r}\text { KUBO } \\
\text { TA }\end{array}$ & 1602572060 & $16 \approx 2572060$ & RADUATORASSY & 8 & $13.829 .500,00$ & 3.807 .168 \\
\hline 7 & $\begin{array}{r}\text { KUBO } \\
\text { TA }\end{array}$ & 1907751010 & 1907751010 & FIP & 4 & $12.317 .300,00$ & 3.692 .997 \\
\hline 0 & $\begin{array}{r}\text { KUBO } \\
\text { TA }\end{array}$ & 1601263010 & 1601263010 & MOTOR, ENGNESTARIER,EECTFCAL & 8 & 12.258.900,00 & 3.791.315 \\
\hline 9 & $\begin{array}{r}\text { KUBO } \\
\text { TA }\end{array}$ & $19077-72060$ & $19077-72060$ & RADLATORASSY & 4 & 10.862.800,00 & 3.524.679 \\
\hline 10 & $\begin{array}{r}\text { KUBO } \\
\text { TA }\end{array}$ & 1644472060 & 1644472060 & RADIATORASSY & 2 & $10.841 .500,00$ & $\mathbf{3 . 5 2 3 . 4 5 6}$ \\
\hline 11 & $\begin{array}{r}\text { KUBO } \\
\text { TA }\end{array}$ & 1602951010 & 1600251010 & PUMP NNECTION & 7 & $8.946 .100,00$ & 2.907 .459 \\
\hline 12 & $\begin{array}{r}\text { KUBO } \\
\text { TA }\end{array}$ & 1603051010 & 1603051010 & PUMPASSYNUECTOR & 8 & $8.946 .100,00$ & 2.907.459 \\
\hline 13 & $\begin{array}{r}\text { KUBO } \\
\text { TA }\end{array}$ & $34070-16800$ & $34070-16800$ & ASSYSTARIER & 6 & $8.799 .300,00$ & 2.859 .75 \\
\hline 14 & кUво & 1023951010 & 1223951010 & $x$ & 7 & $8.504 .600,00$ & 2.763 .984 \\
\hline
\end{tabular}

Gambar 17. Sales promotion

Tabel 8. Laporan keuangan.

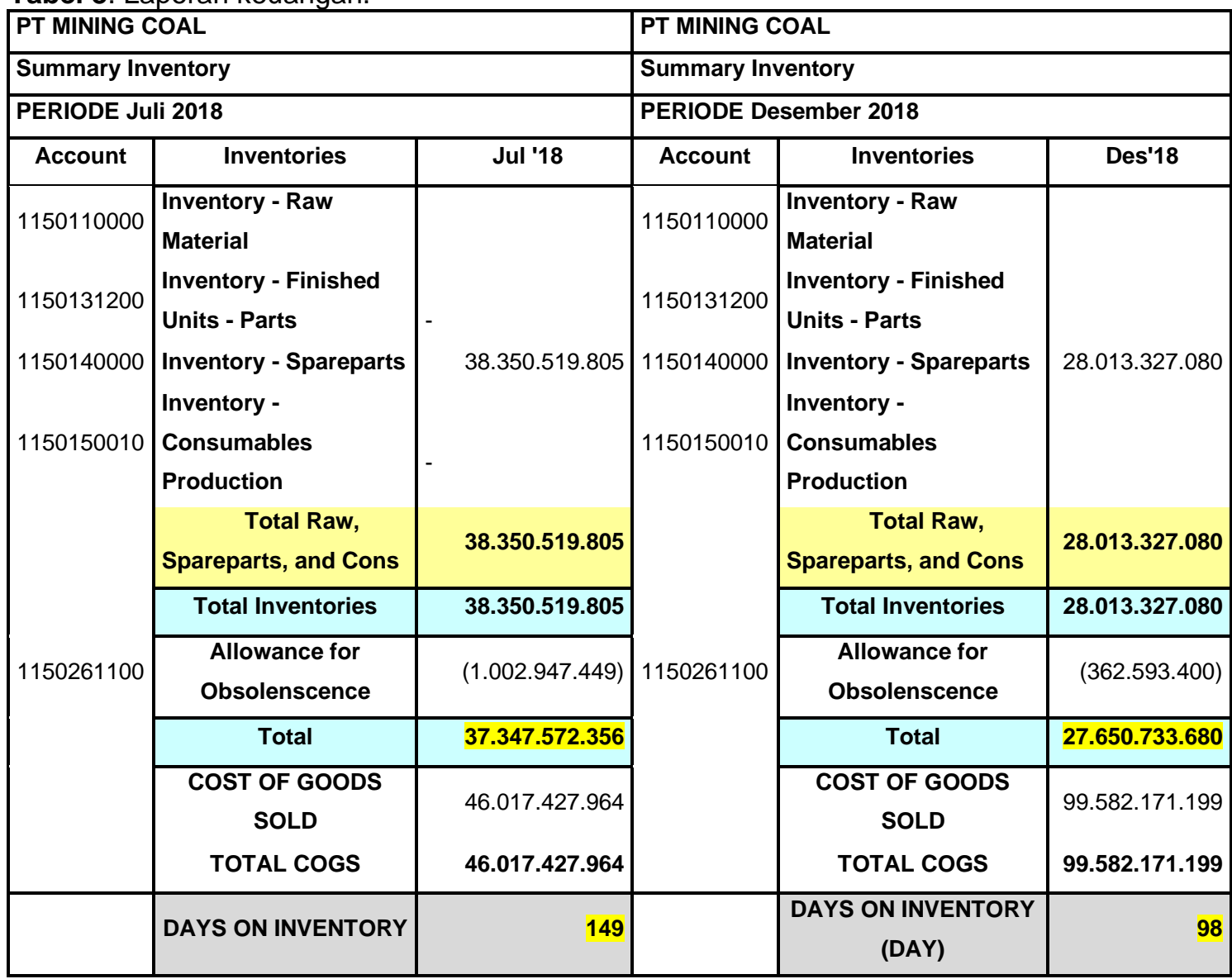

\subsection{Rangkuman}

Setelah dilakukan implementasi terhadap perbaikan yang direncanakan maka didapatkan hasil sebagai berikut sebagaimana yang diperlihatkan dalam Tabel 8:

1. Penurunan terhadap jumlah inventory Part and Service Department dari
37.347.572.356 menjadi 27.650.733.680, yaitu sebesar $26 \%$.

2. Penurunan terhadap days on inventory dari 149 hari menjadi 98 hari days on inventory.

3. Penurunan deadstock dari 11.641 menjadi 8.626 atau terjadi penurunan kurang lebih sebesar $26 \%$. 
Hasil dari perbaikan manajemen inventory menggunakan kombinasi antara pendekatan consignment stock dan marketing mix ternyata dapat memberikan kontribusi yang cukup efektif dalam menurunkan days on inventory dan deadstock. Walaupun pendekatan atau solusi yang diimplementasikan lebih bersifat praktis dan sederhana dibandingkan yang diusulkan [2-11] namun perusahaan mendapatkan keuntungan cukup baik setelah kedua konsep ini diimplementasikan.

\section{KESIMPULAN}

Berdasarkan hasil penelitian yang dilakukan di Departemen Part And Service PT. COAL MINING didapatkan beberapa kesimpulan yaitu : (1) Pengelolaan inventory dapat dilakukan secara baik, efektif, dan efisien dengan menggunakan metode Penjualan Konsinyasi. Ini dibuktikan dengan penurunan jumlah inventory dari 37.347.572.356 menjadi 27.650.733.680, turun sebanyak $26 \%$ serta nilai days on inventory dari 149 hari menjadi 98 hari di Departemen Part And Service PT. COAL MINING. (2) Pengelolaan terhadap deadstock dapat dilakukan dengan mengubah deadstock menjadi permintaan dengan menggunakan metode mix strategy 4P (Product, Place, Price, Promotion) sehingga menghasilkan penurunan nilai deadstock inventory dari 11.641.000.000 menjadi 8.626.000.000., atau turun sebanyak $26 \%$. Penelitian ini dapat dikembangkan lagi dengan mempertimbangkan: (1) Lead time, (2) Service level sebagai variabel keputusan, (3) Kolaborasi terjadinya back-order dan lost-sales, (4) Pola permintaan pada sistem yang probabilistik serta dikembangkan lagi untuk jenis distribusi permintaan yang lain.

\section{DAFTAR PUSTAKA}

[1] S. Axsäter, Inventory Control, vol. 225. Cham: Springer International Publishing, 2015. doi: 10.1007/978-3-319-15729-0.

[2] H. H. Azwir and O. Patriani, "Perbaikan Pengelolaan Pergudangan Melalui Penerapan Sistem Informasi Pergudangan di CV. ABB," J. OPTIMASI Sist. Ind., vol. 16, no. 01, p. 15, 2017.

[3] S. T. Risyahadi (Universitas IPB - Indonesia) and H. Y. Putri (Universitas IPB - Indonesia), "Upaya Improvement Pengendalian Persediaan Suku Cadang Dengan Metode Fixed Time Period Pada PT XYZ," J. Manaj. Ind. Dan Logist., vol. 3, no. 2, pp. 129-140, Nov. 2019, doi: 10.30988/jmil.v3i2.122.
[4] M. Fauzi (Universitas Widyatama - Indonesia) and S. N. Bahagia (Institut Teknologi Bandung - Indonesia), "Analisis Kebijakan Inventori Pada Komponen Darah Packed Red Cell (PRC)," J. Manaj. Ind. Dan Logist., vol. 3, no. 2, pp. 94-105, Nov. 2019, doi: 10.30988/jmil.v3i2.218.

[5] W. Adiani, D. Lesmono, and T. Limansyah, "Model Persediaan dengan Permintaan Bergantung pada Harga Jual dan Tingkat Persediaan dengan Faktor Deteriorasi," J. IIm. Tek. Ind., vol. 18, no. 2, pp. 183-191, Dec. 2019, doi: 10.23917/jiti.v18i2.8749.

[6] R. V. Martono, "Studi Kasus Penerapan Vendor Managed Inventory Pada Sistem Rantai Pasok," vol. 02, no. 01, p. 12, 2018.

[7] E. Fatma and D. S. Pulungan, "Analisis Pengendalian Persediaan Menggunakan Metode Probabilistik dengan Kebijakan Backorder dan Lost sales," J. Tek. Ind., vol. 19, no. 1, p. 38, Feb. 2018, doi: 10.22219/JTIUMM.Vol19.No1.38-48.

[8] H. F. Afianti, H. H. Azwir, J. K. H. Dewantara, and K. Jababeka, "Pengendalian Persediaan Dan Penjadwalan Pasokan Bahan Baku Impor Dengan Metode Abc Analysis Di PT Unilever Indonesia, Cikarang, Jawa Barat," vol. 21, no. 2, p. 14, 2017.

[9] I. Masudin and M. S. Kamara, "Electronic Data Interchange and Demand Forecasting Implications on Supply Chain Management Collaboration: A Customer Service Perspective," J. Tek. Ind., vol. 18, no. 2, p. 138, Sep. 2017, doi: 10.22219/JTIUMM.Vol18.No2.138-148.

[10]D. P. Hasian, "Konsep Persediaan Minimum Maksimum Pengendalian Part Alat Berat Tambang PT Semen Padang," J. Optimasi Sist. Ind., vol. 11, no. 1, p. 203, May 2016, doi: 10.25077/josi.v11.n1.p203-207.2012.

[11]W. A. Jauhari, "Tingkat Persediaan Spare Part Forklift Merek Komatsu Dengan Pendekatan Model Persediaan Single Item," J. IIm. Tek. Ind., vol. 4, no. 3, p. 10, 2006.

[12] T. Wild, Best practice in inventory management, 2. ed. Amsterdam: ButterworthHeinemann, 2002.

[13]E. Constantinides, "The Marketing Mix Revisited: Towards the 21st Century Marketing," J. Mark. Manag., vol. 22, no. 3-4, 
pp. 407-438, Apr. 2006, doi: $10.1362 / 026725706776861190$.

[14] M. Braglia and L. Zavanella, "Modelling an industrial strategy for inventory management in supply chains: The 'Consignment Stock' case," Int. J. Prod. Res., vol. 41, no. 16, pp. 3793-3808, Jan. 2003, doi: 10.1080/0020754031000138330.

[15]G. Valentini and L. Zavanella, "The consignment stock of inventories: industrial case and performance analysis," Int. J. Prod. Econ., vol. 81-82, pp. 215-224, Jan. 2003, doi: 10.1016/S0925-5273(02)00300-6.

[16]L. Zavanella and S. Zanoni, "A one-vendor multi-buyer integrated production-inventory model: The 'Consignment Stock' case," Int. J. Prod. Econ., vol. 118, no. 1, pp. 225-232, Mar. 2009, doi: 10.1016/j.ijpe.2008.08.044.

[17] M. Catena, A. Grassi, and A. Persona, "The Consignment Stock of Inventories in Presence of Obsolescence," Int. J. Prod. Res., vol. 43, no. 23, pp. 4969-4988, 2005, doi: https://doi.org/10.1080/00207540500216631.

[18] M. A. Barsalou, Root Cause Analysis: A StepBy-Step Guide to Using the Right Tool at the Right Time. Boca Raton, FL 33487-2742: CRC Press, 2015.

[19]E. GüRel, "SWOT ANALYSIS: A THEORETICAL REVIEW," J. Int. Soc. Res., vol. 10, no. 51, pp. 994-1006, Aug. 2017, doi: 10.17719/jisr.2017.1832.

[20] N. Altay and L. A. Litteral, Eds., Service Parts Management. London: Springer London, 2011. doi: 10.1007/978-0-85729-039-7.

\section{Biografi Penulis}

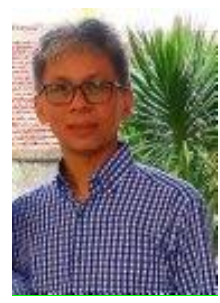

Hery Hamdi Azwir

adalah dosen di Universitas Presiden, Program Studi Teknik Industri. Lahir di Bandung dan meraih gelar Sarjana Teknik Elektro dari Institut Teknologi Bandung (ITB) dengan konsentrasi pada Sistem Komputer, dan Magister Teknik dari Departemen Teknik dan Manajemen Industri juga di ITB.

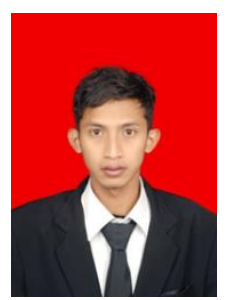

\section{Arif Hidayatullah}

adalah Alumni Strata-1 Universitas Presiden, Program Studi Teknik Industri. Saat ini aktif sebagai Inventory Control Specialist untuk salah satu perusahaan swasta dibidang kelapa sawit, yang berlokasi di head office Jakarta.

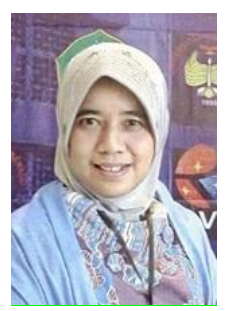

\section{Hirawati Oemar}

adalah dosen tetap di Prodi Teknik Industri Universitas Islam Bandung. Memperoleh gelar Strata 1 di bidang Fisika, Universitas Indonesia dan memperoleh gelar Strata 2 pada bidang Teknik dan Manajemen Industri, Institut Teknologi Bandung 